\title{
Orthotopic Liver Transplantation for Alcoholic Cirrhosis
}

\author{
Thomas E. Starzl, MD, PhD, David Van Thiel, MD, Andreas G. Tzakis, MD, Shunzaburo \\ Iwatsuki, MD, Satoru Todo, MD, J. Wallis Marsh, MD, Babu Koneru, MD, Sandee Staschak, \\ RN, Andrei Stieber, MD, and Robert D. Gordon, MD \\ Departments of Surgery and Medicine, University Health Center of Pittsburgh, University of \\ Pittsburgh, and the Veterans Administration Medical Center, Pittsburgh
}

\section{Abstract}

Fifteen patients with Laennec's cirrhosis underwent orthotopic liver transplantation between 1963 and the end of 1979. The first eight patients died perioperatively or within two months, but four of the next seven patients had long survival; three are still alive after 11 to 14 years. After the introduction of cyclosporine therapy, 41 more patients with alcoholic cirrhosis were treated with liver transplantation from 1980 to June 1987. The one-year survival is $73.2 \%$, and, after one to three years, $28(68 \%)$ of the recipients are living. Of the 35 patients in the combined old and new series who lived for six months or longer, only two returned to alcohol abuse. Social and vocational rehabilitation has been the rule in these recipients who were selected primarily because of urgency of need, because they or their families insisted on treatment, and because they and their families thereby committed themselves to long-standing programs of alcoholism care.

The use of orthotopic liver transplantation to treat patients with Laennec's cirrhosis has been criticized by health care personnel or even prohibited by agencies responsible for health care funding. ${ }^{1}$ To help judge the merit of such negative attitudes, we have examined the fate of 56 alcoholic recipients of liver transplants treated between 1963 and July 1987, with an emphasis on patients treated after the introduction of cyclosporine-steroid therapy in $1979 .{ }^{2}$

\section{Methods}

The clinical diagnosis of Laennec's cirrhosis was considered when there was a history of habitual and excessive drinking or when there were no other explanations for hepatic cirrhosis. The complete native liver always became available for pathological study. An incorrect diagnosis of alcoholic cirrhosis often had been made by the referring physician if there was no other explanation for the hepatic disease. Patients whose livers did not contain confirmatory evidence were not included as alcoholics in the analyses.

Although abstinence was considered to be a favorable factor, a "dry" period of specific duration was not required since this would have invited systematic falsification of the medical history and because death often would have been the price of a significant wait. Acknowledgment of the alcoholism problem was expected and commitments not to drink in the future were obtained from the patient and family. In recent years, professional counseling and establishment of alcoholism support group-liaisons have been provided from the outset. Urgency of need was defined with a six-tier stratification that was originally developed in 1982 and was recently applied nationally by the United Network for Organ Sharing as one of the factors for the equitable allocation of extrarenal organs. ${ }^{3}$ The six urgency classifications are defined as follows: (1) working or in school; (2) confined to 
home, self-care: (3) confined to home, requiring professional care; (4) hospital bound, not in an intensive care unit (ICU); (5) hospital: bound, in an ICU; (6) in an ICU, unconscious and on ventilator. This United Network for Organ Sharing distribution system does not penalize for alcoholism.

\section{Case Material}

Precyclosporine Era-Of 170 recipients of orthotopic liver transplants treated from March 1963 through 1979, eighty-four were adults and 15 (18\%) of these adults had alcoholic cirrhosis. The alcoholic recipients were $38.1 \pm 9.0(\mathrm{SD})$ years old (range, 27 to 47 years). Thirteen were males and two were females. Debilitation and severe encephalopathy contributed variably to a uniformly high risk. All of the 15 recipients were in urgency class 4,5, or $6 .^{3}$

The patients were treated at the University of Colorado Medical Center, Denver. Immunosuppression during this 17 -year period has been summarized elsewhere. ${ }^{4}$ The usual treatment was with azathioprine and prednisone to which antilymphocyte globulin almost always was added. In a few cases, cyclophosphamide was interchanged with azathioprine and thoracic duct drainage was occasionally used. ${ }^{4}$

Cyclosporine Era-The patients were treated at the Presbyterian University Hospital of the University Health Center of Pittsburgh, after referral from all parts of the United States. Cyclosporine and steroids always were used at the outset. In a few cases, azathioprine was added or used to replace the cyclosporine. After September 1984, monoclonal OKT3 therapy was given intravenously for steroid-resistant rejections. ${ }^{5}$

Of 1000 patients treated from March 1980 to June 1987, six hundred sixty-six were adults. Of these 666 , forty-one (6.2\%) had Laennec's cirrhosis. They were $48.1 \pm 8.8(\mathrm{SD})$ years old (range, 27 to 66 years). There were 32 males and nine females. Thirty-six of the 41 patients were in urgency classes 4 to 6 . Fourteen of them were in the ICU and in most instances were receiving ventilatory assistance. The other five patients ranged between class 3 (home with professional care) and class 4 (hospital bound).

\section{Drinking and Rehabilitation History}

Quantitative estimates of alcohol intake preoperatively were not considered reliable nor were estimates of the time of abstinence preceding activation of candidacy. In contrast, the close medical supervision in the postoperative period made concealment of drinking almost impossible. Blood alcohol levels could be obtained for objective confirmation if relapse was suspected but the need for this was uncommon.

Rehabilitation was accurately assessed postoperatively by employment records and by the resumption of definable domestic functions. Less uniform indexes included the resumption of education or the repair of previously disrupted social and personal relationships.

\section{Multidisciplinary Support}

The modern understanding of alcoholism and its treatment evolved during the 25-year period of case accrual. For much of this time, little formal effort was made at counseling and behavior modification. However, in the last two years, extensive psychiatric and social support has been systematically provided, as will be reported separately. The remarkable fact was that the record compiled was achieved for the most part without such advantages, as if the liver transplantation itself had been the ultimate sobering experience. 


\section{Survival Analysis}

Kaplan-Meier survival curves, including Breslow, Tarpne-Ware, and Mantel-Cox probability statistics, were produced using the $1 \mathrm{~L}$ survival analysis module of BMDP/PC statistical software (BMDP Statistical Software, Los Angeles) on a microcomputer. ${ }^{6}$

\section{Results}

\section{Precyclosporine Era}

Survival-The first eight alcoholic recipients died perioperatively or within two months. However, four of the next seven survived for $4 \frac{1}{2}$ to 14 years and three are still alive. The Kaplan-Meier survival curve for the 15 patients treated in the precyclosporine era is shown in Fig 1.

Recidivism and Rehabilitation-The three surviving patients are in good health with normal liver function after $14.11 \frac{1}{2}$, and 11 years, respectively. None has returned to drinking. One of these patients works in a state engineering department. The second patient became a chief of an Indian tribe, and the third is a clerk.

The fourth long-term survivor died of pneumonia after $4 \frac{1}{2}$ years. As described previously, ${ }^{4}$ he had relapsed into drug abuse and alcoholism. This patient had been unconscious when a decision was made for transplantation. When he awakened from his coma, he was angry at having been rescued. The complex social and psychiatric issues in this case have been reported most completely in the nonmedical literature. ${ }^{7}$

\section{Cyclosporine Era}

Survival-The Kaplan-Meier survival curve for the 41 patients treated in the cyclosporine era is shown in Fig 1. Follow-up in this group is from one to three years. The one-year survival is. $73.2 \% \pm 6.9 \%$. Twenty-eight $(68.3 \%)$ of the 41 patients are still alive, two by virtue of retransplantation three days after the primary operation. A third patient died after retransplantation at $5 \frac{1}{2} 2$ weeks. Only two patients died late, one after 714 days of metastases from an incidental hepatoma in the native liver, and the other after 623 days of liver failure. There have been no late retransplantations. Figure 2 demonstrates no significant difference between the survival of the 41 patients who received transplants for alcoholic cirrhosis when compared with the survival of 625 adults who received transplants for other causes of endstage liver disease.

The number of cases was too small to assess the influence on surnval of alcohol abstention at the time of transplant candidacy. Thirty-four patients had stopped drinking when they were admitted for transplant evaluation, frequently because they were too sick to imbibe any longer. Twenty-four (70.6\%) of these 34 are still living ten to 36 months after transplantation. The one late death after 714 days was caused by recurrent hepatoma. The other seven patients were drinking until the time of the admission that led to transplantation. Two of these patients died perioperatively, and another died after 623 days. The remaining four are alive after 22 to 26 months.

Recidivism-Of the 30 recipients in the cyclosporine era who lived for at least six months, the only one who resumed drinking was the patient who died after 623 days. This was a 38year-old man who had been an exceptional university athlete, a respected teacher subsequently, and finally the target of a career-ending accusation of sexual abuse by one of his high school students. When first seen, he was encephalopathic, toxic from recent drinking, and a class 6 candidate who required ventilatory support. His family did not accept 
the diagnosis of alcoholism then, or later. His recovery after liver transplantation was slow. Within a few months after discharge, he resumed the toxic drinking that led to his death.

Rehabilitation-A remarkable record of rehabilitation was established by the 30 patients in the cyclosporine era who survived for at least six months. Twenty-seven returned to jobs or fully maintained their households. One was disabled with back pain, one retired, one who returned to drinking held a job until shortly before he died after 623 days, and a fourth was dys-functional because of borderline mental retardation.

\section{Comment}

The hope that patients with Laennec's cirrhosis could be helped by liver replacement was dashed in the early days of hepatic transplantation by the death within two months of the first eight alcoholic recipients. ${ }^{4,8}$ Alcoholics seemed too physically and emotionally frail to withstand the rigors of such a large operation and subsequent immunosuppression.

Nevertheless, even before 1980 and the introduction of cyclosporine-steroid therapy, four of the next seven alcoholic patients recovered fully after liver transplantation and three are still alive after 11 to 14 years. Since 1980, the results with alcoholic patients have been as good as in adult patients with a broad spectrum of other hepatic diseases (Fig 2). In fact, the results have been better than with diseases that can recur in the transplanted liver such as type B hepatitis, hepatic malignancies, and Budd-Chiari syndrome. ${ }^{9}$

Howeyer, there has been no consensus that the ability to treat patients dying of Laennec's cirrhosis implies an obligation to do SO.,10,11 To the extent that objections to liver transplantation are moralistic, these undermine the modern understanding of alcoholism including the recognition that this is a treatable disease, not a vice. ${ }^{1}$ How liver transplantation fits into the continuum of treatment and if it can be afforded by society should be the important questions.

The fact that relapses of alcoholism have been uncommon after hepatic transplantation weakens the potential objection that provision of a new liver is a futile gesture as well as the waste of an organ. Going through a trauma of such magnitude as liver transplantation seemingiy has been the starting point almost invariably for long or permanent abstention and usually for rehabilitation. Our only relapses were in two patients who, after transplantation, appeared to resent what had been done while they were in a coma or mentally incompetent. Thus, the will of the patient to live may be the most important selection factor. Not far behind may be an explicit admission of alcoholism by the patient and his family and an expression of determination to effect behavior-al change. Most of our patients had established these qualifications before our evaluation of their candidacy. The good results after transplantation may reflect a high degree of self-screening from a much larger pool.

If these are valid criteria for candidacy screening, the imposition of an arbitrary period of abstinence before going forward with transplantation would seem medically unsound or even inhumane. By waiting unnecessarily, reasonable candidates would be allowed to deteriorate to a poor-risk category, and those at poor risk from the outset weald almost surely die during the interim.

Using expenses as an argument against liver transplantation would be equally illogical unless an even more drastic decision were taken to withhold all treatment from patients dying of Laennec's cirrhosis and perhaps other liver ailments. The cost of treating complications of terminal hepatic cirrhosis can be astronomical ${ }^{12}$ even without procedures such as portosystemic shunts and other intra-abdominal operations used to control hemorrhage from esophageal varices and especially if operations are employed. Not only is 
this kind of care expensive, but it Provides no hope of altering the disease and little hope of social and vocational rehabilitation.

\section{Acknowledgments}

This study was supported by research grants from the Veterans Administration and precect grant AM 29961 from the National Institutes of Health, Bethesda. Md.

\section{References}

1. Flavin DK, Niven RG, Kelsey JE. Alcohoilsm and orthotopic liver transplantation. JAMA. 1988; 259:1546-1547. [PubMed: 3276937]

2. Starzl TE, Klintmalm GBG, Porter KA, et al. Liver transplantation with use of cyclosporin A and prednisone. N Engl J Med. 1981; 305:266-269. [PubMed: 7017414]

3. Starzl TE, Gordon RD, Tzakis A, et al. Equrable allocation of extrarenal organs: With specal reference to the liver. Transplant Proc. 1988; 20:131-138. [PubMed: 3278456]

4. Starzl TE, Iwatsuki S, Van Thiel DR, et al. Evolution of liver transplantation. Hepatology. 1982; 2:614-636. [PubMed: 6749635]

5. Fung JJ, Demetria AJ, Porter KA, et al. Use of OKT3 with cyclosporine and steroids for reversa of acute kidney and liver allograft rejection. Nephron. 1987; 96:19-33. [PubMed: 3306422]

6. Kaplan EL, Meier P. Nonpanmetric estimaation from incomplete Observations. J Am Stat Assec. $1958 ; 53: 457-481$.

7. Morgan, T. Literary Outlaw: The Litc, and Times of William S. Burroughs. Henry Holt \& Co.; New york: 1988. Billy; p. 495-536.

8. Starzl TE, Putnam CW, Ishikawa M, et al. Currnent policies in hepatic transplantation: Candidacy of patients with alcoholic liver disease or preformed antidonor antibodies and a reappraisal of biliary duct reconstruction. Ann NY Acad Sci. 1975; 252:145-158. [PubMed: 1096710]

9. Iwatsuki S, Starzl TE, Todo S, et al. Experienes in 1000 liver transplants under cyclosporine-steroid therapy: A survival report. Transplant Proc. 1988; 20:498-504. [PubMed: 3279643]

10. Liver transplantation. CONSENSUS CONFERENCE. JAMA. 1983; 250:2961-2964. [PubMed: 6417356]

11. Lundberg GO. License to plunder or to paint. JAMA. 1983; 250:2966-2967. [PubMed: 6358553]

12. O'Donnell TF, Gembarowicz RM, Callow AD, et al. The economic impact of acute variceal bleecing: Coat-effectiveness implications for medical and surgical therapy. Surgery. 1980; 88:693-701. [PubMed: 6776645] 


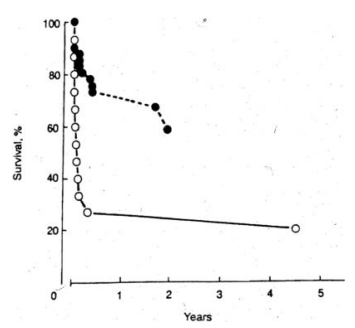

Fig 1.

Survival (Kaplan-Meier method) atter liver transplantation for alcoholic cirrhosis for 15 palients treated in precyclosporine era (open circles) and 41 patients treated with cyclosporine (solid circles). Differences in survival during these two trealment periods are significant $(P<.001)$. 


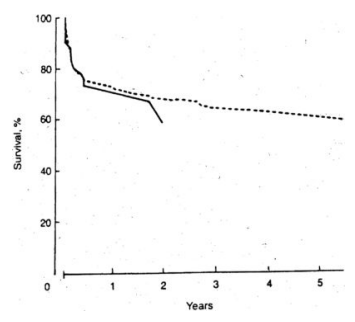

Fig 2.

Survival (Kaplan-Meier method) after liver transplantation for alcoholic cirrhosis of 41 patients treated wrth cyclosporine (solid line) is compared with survival of 625 adult patients who received transplants for other causes of liver failure (dashed line). All patients were treated with cyclosporine. There is no significant difference in survival between the two groups of patientS $(P>.77)$. 